\title{
Gestural coupling and social cognition: Möbius Syndrome as a case study
}

\author{
Joel Krueger ${ }^{1 *}$ and John Michael ${ }^{2}$ \\ Center for Subjectivity Research, University of Copenhagen, Copenhagen, Denmark \\ GNOSIS Research Centre, Aarhus University, Copenhagen, Denmark
}

\author{
Edited by: \\ Chris Frith, Wellcome Trust Centre \\ for Neuroimaging at University \\ College London, UK \\ Reviewed by: \\ Jonathan Cole, Poole Hospital, UK \\ Antonia Hamilton, University of \\ Nottingham, UK \\ *Correspondence: \\ Joel Krueger, Center for Subjectivity \\ Research, University of \\ Copenhagen, Njaslgade 140-142, \\ DK-2300 Copenhagen S, Denmark \\ e-mail: joelk@hum.ku.dk \\ The authors contributed equally to \\ this work.
}

Social cognition researchers have become increasingly interested in the ways that behavioral, physiological, and neural coupling facilitate social interaction and interpersonal understanding. We distinguish two ways of conceptualizing the role of such coupling processes in social cognition: strong and moderate interactionism. According to strong interactionism (SI), low-level coupling processes are alternatives to higher-level individual cognitive processes; the former at least sometimes render the latter superfluous. Moderate interactionism (MI) on the other hand, is an integrative approach. Its guiding assumption is that higher-level cognitive processes are likely to have been shaped by the need to coordinate, modulate, and extract information from low-level coupling processes. In this paper, we present a case study on Möbius Syndrome (MS) in order to contrast $\mathrm{SI}$ and MI. We show how MS-a form of congenital bilateral facial paralysis—can be a fruitful source of insight for research exploring the relation between high-level cognition and low-level coupling. Lacking a capacity for facial expression, individuals with MS are deprived of a primary channel for gestural coupling. According to SI, they lack an essential enabling feature for social interaction and interpersonal understanding more generally and thus ought to exhibit severe deficits in these areas. We challenge SI's prediction and show how MS cases offer compelling reasons for instead adopting MI's pluralistic model of social interaction and interpersonal understanding. We conclude that investigations of coupling processes within social interaction should inform rather than marginalize or eliminate investigation of higher-level individual cognition.

Keywords: Möbius Syndrome, social interaction, social cognition, theory of mind, emotion recognition, facial paralysis, behavioral coupling

\section{FROM MINDREADING TO COUPLING: STRONG AND MODERATE FORMS OF INTERACTIONISM}

Social cognition refers to the capacity to understand and interact with others in contextually appropriate ways. Among other things, it involves the ability to interpret mental states and behavior: for example, to see actions and bodily expressions as expressing particular emotions or intentions. For several decades, the "Theory of Mind" paradigm was the dominant way of understanding social cognition (Premack and Woodruff, 1978). According to this paradigm, social cognition is a process of mental state attribution or "mindreading." We understand or "read" others' behavior by attributing mental states to them; these mental states are what allow us to interpret and predict current and future behavior. Two competing proposals were offered to account for the mechanisms enabling mindreading. According to Theory, we use lay theories about how minds work to infer the existence of mental states in others and interpret their expressions and behavior (Perner, 1991; Gopnik and Wellman, 1992). Simulation Theory, on the other hand, argues that we use our own emotional, cognitive, and imaginative resources-either consciously and deliberately or unconsciously and automatically — to model others' mental states. This simulation process is the basis of our ability to understand their mental life (Gordon, 1986; Gallese, 2001; Goldman, 2006).
In recent years, an increasingly influential movement has stressed the primacy of interaction in facilitating social understanding. This so-called "interactive turn" (de Jaegher et al., 2010) urges us to reconsider the individualistic orientation of the mindreading paradigm. According to the interactionist, this paradigm is individualistic in that it wrongly assumes that the mechanisms enabling social cognition lie exclusively within the individual brain. But this individualistic focus overlooks the way that social cognition is fundamentally shaped by the broader temporal, perceptual, and interactive dynamics of embodied engagement. Interactionism thus "rejects the spectatorial supposition that we are primarily spectators or observers of others' behaviors. Our normal everyday stance toward the other person is not thirdperson, detached observation; it is second-person interaction" (Gallagher, 2008, p. 164). Interactionism explanatorily prioritizes structures and processes spanning multiple agents-including, crucially, the coordinative patterns of verbal and non-verbal behavior that determine the temporal character and qualitative back-and-forth flow of an encounter. Interactionism thus endorses a move away from thinking of social cognition as an individualistic process of mental state attribution to one of participatory engagement. The latter is characterized as a dynamic, flexible, and reciprocal process jointly constructed in real-time by multiple participants. 
Drawing upon dynamical systems theory, interactionists conceptualize engagement and render it methodologically tractable by appealing to the notion of "coupling," which de Jaegher and colleagues define as "the influence between a system's variables and another system's parameters” (de Jaegher et al., 2010, p. 441; cf. also Spivey, 2007; Thompson, 2007; Marsh et al., 2009). In slightly less technical terms, two systems can be said to be coupled "when the conduct of each is a function of the conduct of the other" (Thompson, 2007, p. 45). For example, it has been documented that two pendulums in adjacent rooms will tend toward synchrony because they influence each other via minute vibrations in walls and floors (Winfree, 2001; Bennett et al., 2002). Or, to take a biological example, Buck and Buck (1976) describe a species of firefly living in Southeast Asia, in which the individual flashing behavior is synchronized at the group level through the visual influence of the collective flashing pattern on the individuals.

Nor is coupling just an exotic phenomenon occurring only in pendulums and certain non-human organisms: think of the wellknown phenomenon that arises when you are walking along a narrow path and somebody comes from the other direction and each tries to avoid the other. Each person's movement (shifting to the right or to the left) constrains the other person's movement, which sometimes causes the two individuals to become coupled to each other in an interaction that is not planned or controlled at the level of individual cognition. Thus, according to de Jaegher and Di Paolo (2007, p. 493), the best way to explain and predict the course of this interaction is by modeling the interaction as such, not the individuals' intentions.

To see how the role of coupling within social interactions can be investigated experimentally, consider the famous study by Murray and Trevarthen (1985) in which a baby and a mother interact via video. In the test condition, the live video of the mother that the baby sees is replaced by a video of the mother from an earlier sequence in the interaction; this upsets the baby just as much as if the mother's face suddenly goes blank (i.e., the "still face" condition (Tronick et al., 1978) and she no longer expresses anything. In this case, we might characterize the structure of the social interaction as the coupling of two systems: the baby is interested not just in the mother's expressiveness but in being coupled to her, that is, in mutually engaging with and influencing her reactions, which in turn shape the infant's own responses. In some other cases, it can also be fruitful to investigate the coupling of subcomponents of a larger interaction: for example, the coupling of behavioral (e.g., gestures), physiological (e.g., heart rate) or neural (e.g., electrical activity) processes that unfold naturally in social engagements (de Rugy et al., 2006; Richardson et al., 2007; Knoblich and Sebanz, 2008; Oullier et al., 2008; Schmidt and Richardson, 2008).

In the following, we will contrast two ways of conceptualizing the role of coupling processes in social cognition. According to what we shall call strong interactionism (SI), coupling processes are explanatory alternatives to the lay theories and simulations postulated by mindreading approaches. SI claims that online interaction carries the weight of social understanding. It is variously (depending on the specific account in question) conceived of as necessary, sufficient, or both necessary and sufficient for social cognition. ${ }^{1} \mathrm{SI}$ is thus a sectarian perspective. It regards the shared dynamics of interaction as alternatives to individual cognition. Moderate interactionism (MI), on the other hand, aims to offer explanations that integrate individual processes with shared coupling processes. It is apparent that both types of approach ascribe a key coordinating role to coupling processes in sustaining social interaction and understanding. However-and this is the crucial point-SI and MI are nevertheless, respectively committed to different conceptions of the relationship between (1) shared coupling processes and (2) individual cognitive capacities (e.g., working memory, attention, control, consciousness) and processes (e.g., mindreading, monitoring, prediction, reasoning).

Our primary aim in contrasting these two positions is to articulate distinct conceptual alternatives (and to give reasons for favoring one of them) — and not, then, to argue that any particular theorist is best interpreted as endorsing either of the alternatives. Nevertheless, for the purpose of illustrating these two positions, we will cite some theorists who appear, at least in the passages we refer to, to be attracted to one or the other. It is important to emphasize, however, that we do not intend to preclude the possibility that some or most of the theorists cited in connection with SI would ultimately agree with us that MI is a more balanced and fruitful alternative. Indeed, if so, so much the better.

Shaun Gallagher, for example, has at times appeared to exemplify SI. Gallagher $(2001,2008)$ has offered a developmental argument to the effect that the embodied responses making up so-called "primary intersubjectivity" (cf. Trevarthen, 1979)— responses present early in childhood and which remain centrally important even in adults - are independent of an ability to mentalize. Such embodied responses as affect attunement (Stern, 1985), neonate imitation (Meltzoff and Moore, 1977), and gaze following (Senju et al., 2006), which are elicited within social interactions, help to couple agents to each other and thereby to sustain interaction and mutual understanding. Since children do not tend to pass explicit false belief tests until they are $4-5$ years old, ${ }^{2}$ as Gallagher notes, there is a prima facie case to be made that many of these embodied social responses are developmentally prior to and thus independent of an ability to mentalize.

More recently, some researchers working in the enactivist tradition (e.g., Auvray et al., 2009; Fuchs and de Jaegher, 2009; de Jaegher et al., 2010; Froese and Di Paolo, 2010), have offered what we consider to be strong interactionist interpretations of the role of coupling in social interactions such as the aforementioned double-video experiment. Auvray and colleagues (2009), for example, raise the question whether the role of coupling in sustaining this sort of interaction must be accounted for in individualistic terms. They ask if it is necessary or appropriate to ascribe to each individual agent an ability to detect an intentional

\footnotetext{
${ }_{1}$ There are a number of more fine-grained distinctions we might consider in interpreting this claim; these distinctions need not concern us here. For extended discussions, see Overgaard and Michael (Under review) and Michael, 2011.

${ }^{2}$ Evidence for implicit false belief understanding in children as young as 11 months obviously puts pressure on this argument, but that is beyond the scope of this paper (see Apperly and Butterfill, 2009; Baillargeon et al., 2010; Michael, 2011; for overviews of this research).
} 
subject who is perceptually directing her movements in a way that is contingent upon the agent's own perceptually directed movements. Alternatively, Auvray and colleagues propose the possibility that "some of the mechanisms underlying the recognition of others are intrinsic to the shared perceptual activity itself (i.e., intrinsic to the interdependence between the two perceptual activities)" (Auvray et al., 2009, p. 34). As de Jaegher and Di Paolo (2007) put it: "If pendulum clocks can do it without mechanisms for 'timing the beat' and 'forming a temporal estimate,' why can't babies? In our perspective, what infant and mother do in this example is possible through the interaction alone" (499). Similarly, in discussing the importance of sensory contingencies in coordinating interactions, Di Paolo et al. (2008) deny that individuals must recognize their mutual coupling in order for it to play a coordinated role. Rather, "interaction can dynamically create phenomena that do not directly result from the individual capacities or behaviors of any of the partners if investigated on their own" (279).

In a sort of theoretical culmination of this work on the role of coupling in social interactions like the one devised for the doublevideo experiment, ${ }^{3}$ de Jaegher et al. (2010) argue that there are a range of cases in which the constitutive role played by emergent systems, (i.e., by coupled interactions) in social cognition "replaces individual mechanisms" such as mindreading (de Jaegher et al., 2010, p. 441). They urge that "if we take seriously the idea that interaction can enable and constitute social cognition, we can conceive of interaction dynamics as, in some cases, delivering the necessary cognitive performance. There is no need to duplicate their effects by an individual mechanism" (de Jaegher et al., 2010, p. 445). ${ }^{4}$ Call this the "reduplication thesis": the idea that, if coupling processes and other features of interactions are shown to be sufficient for facilitating social understanding, we need not reduplicate their functions by appealing to individualistic mechanisms.

$\mathrm{MI}$, in contrast, is an integrative approach. Its guiding assumption is that higher-level cognitive processes are likely to have been shaped by the need to coordinate, modulate, and extract information from low-level coupling processes. Investigation of coupling processes should inform rather than marginalize or eliminate the investigation of individual cognitive processes. To see how this general conception contrasts with SI, consider an alternative, more moderate way of understanding the double-video experiment. Rather than saying that the features of the interaction itself explain the baby's reaction, one might say that the baby processes not only a stimulus but also features of the interaction. Gergely and Watson (1996), for example, attribute the infants' differential responses to cognitive mechanisms in the infant such as an innate contingency detector. Similarly, describing motherinfant interactions in which the mother amuses the infant by continually repeating an utterance and each time stretching both its duration as well as the intervals between utterances, Daniel Stern writes: "there could be no such effect ... unless the infant had some mechanism for timing the beat and forming a temporal estimate of when the next beat should fall" (2002/1977,

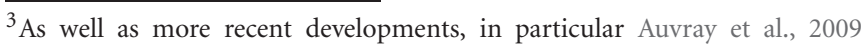
perceptual crossing experiment.

${ }^{4}$ For similar statements, see de Jaegher and Froese, 2009, and Di Paolo, 2009.
}

p. 114). The interpretations offered by these theorists are more moderate insofar as they envision a crucial role for individual cognitive processes in detecting and sustaining coupling. Indeed, they suggest the strategy of treating the interactive experiment as a means to elicit coupling in order to test hypotheses about individual cognitive processes that detect and/or sustain it. ${ }^{5}$ Although this strategy may be superfluous in some simple cases in which the behavior of coupled systems can be adequately explained at the level of the interaction as such (e.g., the synchronization of pendulums), we submit that it is a more promising option in complex cases involving more sophisticated systems such as living organisms. Even the synchronization of flashing in fireflies involves processes ( simple heuristics, algorithms, etc.) within the individual fireflies; the systems-level analysis does not replace but rather complements the otherwise incomplete picture that we get by looking at processes in individual fireflies. And once we turn our attention to such sophisticated creatures as human beings, it is all the more compelling to suppose that various kinds of individual cognitive processes are integrated in diverse and subtle ways with coupling processes that span multiple individuals. Thus, in the aforementioned example of two people trying to pass by each other on a narrow path, individual intentions and action plans (e.g., to avoid coupling, to shift to the left, etc.) are after all playing a role in generating the coupling, even though they are not having the effect that the individuals desire or expect them to have. From a moderate perspective, then, individual cognitive processes are part of the picture of what is going on in these cases. In short, MI adopts an ecumenical perspective; it sees social cognition as a diverse collection of processes and strategies for navigating the interpersonal world.

Again, both SI and MI attribute a central role to coupling processes and other features of online interactions. But they disagree about the relationship between these interactive elements and individual cognitive capacities and processes. They also differ in the predictions they generate about cases in which coupling processes are missing or somehow compromised. In what follows, we use Möbius Syndrome (MS) as a litmus test to contrast and evaluate these predictions. Since they lack facial expressions, people with MS are deprived not only of an important means of expressing their emotions ${ }^{6}$ but also of a primary channel for behavioral coupling - and thus of an essential enabling feature of social interaction. And if coupling processes are necessary for social understanding, as some SI proponents appear to suggest, it would seem that social understanding in people with MS ought to

\footnotetext{
${ }^{5}$ For other statements of what we would call MI, see for example, Michael (2011), who calls his position "modest interactionism"; Sutton et al. (2011), who espouse a similar conception of the relationship between embodiment and higher-level cognition; Herschbach, 2011, who defends an integrative, multi-level conception based on mechanistic ideas.

${ }^{6}$ As we will see, one of the intriguing suggestions we might draw from MS cases is a strongly embodied conception of emotion: that is, the idea that the experiential character of at least some emotions is deeply dependent upon various forms of bodily expression (facial expressions, gestures, and whole-body expressions). So, rather than consisting of relatively brief physiological states (Izard, 1974; Panskepp, 1992; LeDoux, 1996), aspects of certain emotions may instead be distributed across the expressive dynamics of the visible, tangible body — as well as the social interactions the body enters into (see Krueger, forthcoming; see also Griffiths and Scarantino, 2009).
} 
be likewise significantly affected. Similarly, if coupling processes are sufficient for social understanding, there is no reason to expect that de-coupled individual strategies would emerge to "reduplicate" what coupling processes already achieve. SI thus predicts that individuals with MS should exhibit deficits in certain aspects of social interaction and understanding.

There is some support for these predictions, which we discuss below. However, we argue that the deficits are neither as severe nor as comprehensive as SI predicts. Moreover, SI cannot account for differences within the population of individuals with MS. There is evidence that individuals with MS adopt a range of strategies to compensate for their lack of facial expression. Some of these strategies not only compensate for the absence of information otherwise provided via facial expressions but also enable alternative forms of coupling: coupling of hand gestures and other bodily movements, conversational and emotional alignment, etc. As we will see, however, these compensatory strategies emerge via explicitly high-level cognitive (i.e., individualistic, reflective) processes. But this stands in contrast to SI's predictions. In contrast to SI, MI does predict that individuals with MS will avail themselves of such high-level cognitive strategies, and that this may also lead to alternative forms of coupling. We turn to this discussion now.

\section{THE INVISIBLE SMILE7: PSYCHOSOCIAL EFFECTS OF MS}

MS is a rare form of congenital facial paralysis-normally complete and bilateral-resulting from maldevelopment of the sixth and seventh cranial nerves (Briegel, 2006). People with MS are unable to form any sort of facial expression; ${ }^{8}$ they also lack ocular abduction and thus tend to move their entire head when tracking objects in their environment. Accordingly, they lack access to basic physical resources that most of us take for granted when expressing emotion, including an ability to provide face-related social cues to others. ${ }^{9}$

Studies of individuals with facial movement disorders have found various kinds of psychological distress, which impairs the quality of their social and physical functioning (Bogart and Matsumoto, 2010b). For example, people with various facial neuromuscular disorders exhibit considerably higher levels of anxiety than the general population (van Swearingen et al., 1998, 1999). ${ }^{10}$ Another study found similar results in individuals with various other visible disfigurements including burns, head and hand conditions, vascular anomalies, skin conditions, and rheumatic diseases (Rumsey et al., 2004). In one of the few studies specifically on MS, individuals were found to exhibit traits of inhibition,

\footnotetext{
${ }^{7}$ The phrase "the invisible smile" is borrowed from the title of a book by Cole and Spalding (2009).

${ }^{8}$ The absence of movement leads facial muscles to atrophy, which can give the face a smooth look with a slack, half-open mouth (Cole and Spalding, 2009, p. 3).

${ }^{9}$ Others parts of the condition include small tongue (which leads to difficulties feeding and speaking), breathing difficulties, malformation of arms or legs (e.g., missing fingers, underdeveloped calf muscles and extremely high arched feet), associated movement difficulties (e.g., clumsiness, late development sitting and standing, difficulties in running, jumping, and hopping, etc.) (see Cole and Spalding, 2009, pp. 2-5).

${ }^{10}$ But see Bogart and Matsumoto (2010b) for some compelling reasons to be cautious when generalizing results from these studies to individuals with MS.
}

introversion, and heightened feelings of social inadequacy and inferiority (Briegel, 2007).

These results are not surprising given the centrality of facial expression in facilitating social interaction. Our face is the locus of our social identity. When we perceive others, there is something experientially unique about our encounter with the face (Levinas, 1969). One reason for this is the fact that the face is a rich multimodal source of socially salient information. Consider the role of basic facial expressions. Although we begin practicing facial expressions in the solitude of the womb (Reissland et al., 2011), smiles, for example, occur mainly in social contexts (Kraut and Johnston, 1979; Jones et al., 1991). Smiles don't merely express positive affect. They also have a social function. Smiles relay intentions to further ongoing interactions, elicit positive reciprocal responses, convey appraisals, and promote cooperation and social cohesion (van Swearingen et al., 1999).

We respond to smiles and other facial expressions because our face recognition abilities are well-developed from birth. Infants are born with a predisposition toward face-related stimuli: they are able to discriminate faces from other stimuli (Mondloch et al., 1999), preferentially track moving face stimuli (Johnson et al., 1991), and within days of birth discriminate between the faces of different people (Walton et al., 1992; Bushnell, 2001). Infants quickly show a preference for their mother's face and attractive faces, and minutes after birth can imitate facial expressions such as tongue protrusion and mouth opening (Meltzoff and Moore, 1997; Slater and Quinn, 2001). ${ }^{11}$ In adulthood the face retains a special experiential status. Facial appearance (including expressiveness or lack thereof) is often seen as an expression of a person's character (Berry and McArthur, 1986). And it is telling that individuals with social phobias tend to avoid looking at faces (Chen et al., 2002). Face perception is thus special, phenomenologically and functionally. ${ }^{12}$ From the moment we enter the world until the moment we leave it, the face is the center of gravity for our social interactions. ${ }^{13}$

\footnotetext{
${ }^{11}$ These findings have not gone uncontested. See Anisfeld, 2005 and Jones, 2009.

${ }^{12}$ It even appears to be sub-served by discrete mechanisms and brain regionssuch as the fusiform face area (Kanwisher et al., 1997; Spiridon and Kanwisher, 2002) - selectively involved in perceiving and exploring face-based social information (Nelson, 2001; Adolphs, 2006).

${ }^{13}$ This is not to deny the importance of social information provided by other channels (voice/prosody, gesture, language, spatial proximity, etc.) in facilitating social understanding. We encounter others as embodied subjects; they are given via perceptual gestalts comprised of multiple channels of information (see the discussion of "coupled strategies" below). Nor is this intended to deny the importance of others' reactions in shaping the character and development of our social competence. Indeed, an important lesson from MS, we suggest, is that part of their (i.e., people with MS) social struggles arise due to others' inability to competently deal with facial difference. For example, some young children with MS are assumed to be retarded because of difficulty in feeding, drooling, and dysarthric speech. This assumption clearly alters how they are treated and has consequences for their socialcognitive development. For those whose faces do not conform to the norm, the social exclusion and isolation experienced becomes a source of stress, anxiety, and anguish, which negatively effects psychosocial development as well as personality functioning and mental health (Cooke Macgregor, 1990). We are thus always in relation to others whose responses play a critical role in shaping our own moment-to-moment responses as well as the ontogenesis of our social-cognitive competence.
} 
Not surprisingly, the narratives of individuals with MS betray an acute awareness of feeling out of sync with and misunderstood by others (Cole and Spalding, 2009). Indeed, many people are illequipped to engage with facial difference, finding it off-putting or frightening. One reason is that facial expressions provide information about the mental states of the individual producing them. Without this expected information, however, an interactant may feel uncomfortable or confused about what the other person is thinking or feeling. ${ }^{14}$

Both SI and MI suggest that there may be an additional reason for the social difficulties people with MS encounter, one which centers on behavioral coupling. Facial expressions don't only provide information about another's mental states. ${ }^{15}$ They also enable at least two kinds of behavioral coupling-movement synchrony and motor mimicry (in particular facial mimicry) — that play a central role in driving social interaction and understanding. Could it be that the absence of these two kinds of coupling is an additional source of social difficulties for individuals with MS? We consider this idea now.

\section{GESTURAL COUPLING: SYNCHRONY AND MIMICRY}

When we engage with others, there is, in addition to the content of our spoken utterances, another concurrent layer of implicit bodily communication at work. Social interaction rests on various forms of non-verbal communication including postural and behavioral coordination (Scheflen, 1964; Bernieri and Rosenthal, 1991). Non-verbal information is crucial for successful understanding (Mehrabian, 1971). Considerations of non-verbal communication have a long history. ${ }^{16}$ However, we have only recently recognized how much of it consists of our involuntarily synchronizing with and mimicking the movements, gestures, facial and bodily expressions of others. This level of social interaction is realized in different forms of behavioral coupling.

Consider movement synchrony. Movement synchrony occurs when a precise synchronization between the speech rhythms and bodily movements of two partners unfolds spontaneously within an interaction (Bernieri, 1988). This synchrony can develop at different time scales: from the milliseconds-long coordination of speech and hand gestures (Condon, 1982) to cycles of hour-long conversations (Hayes and Cobb, 1982). It can also emerge in nonverbal contexts like walking (Zivotofsky and Hausdorff, 2007; van Ulzen et al., 2008) and when using rocking chairs (Richardson et al., 2007). Synchronous movement is a form of implicit bodily communication. One of its psychosocial functions is to promote social cohesion, enhancing feelings of connectedness, rapport, and cooperation among interactants (Bernieri, 1988; Hove and Risen, 2009; Wiltermuth and Heath, 2009; Valdesolo et al., 2010). There is further evidence that movement synchrony not only motivates partners to interact but also enhances their ability to

\footnotetext{
$\overline{{ }^{14} \text { Note that this explanation does not necessarily appeal to real, online social }}$ interaction; it may also apply to cases where a detached onlooker is observing an individual with MS from afar or on TV.

${ }^{15}$ Some facial expressions-as well as other bodily expressions and gesturesmay even be part of the ontology of certain emotions states. See Krueger (forthcoming).

${ }^{16}$ See Darwin, 1872/1965, Lipps, 1907, and Smith, 1759/1966.
}

do so (Valdesolo et al., 2010). One reason may be that synchrony increases interactants' attention to one another's movements. Additionally, it may be easier to predict and adapt to the movements of another moving at a similar tempo and initiating movements of a similar size, duration, and force as oneself.

Another form of implicit bodily communication is motor mimicry. Interactants mimic the behavioral patterns of others by adopting similar postures, mannerisms and bodily configurations (Hatfield et al., 1994). This link between perception and behavior-I perceive another's posture or behavior, causing me to assume that posture or behavior, which in turn is perceived by the other and heightens their feeling of rapport—is a kind of "social glue" (Chartrand and Bargh, 1999) facilitating the convergence of emotional states between interactants, thereby heightening feelings of mutual understanding (Hatfield et al., 1994; Lakin and Chartrand, 2003) and increasing pro-social behavior (e.g., picking up another's dropped pen or giving to charity) (van Baaren et al., 2004).

While posture, gestures, and movement are all part of our mimetic repertoire, their mimetic capabilities are somewhat limited in comparison with those of the face. In light of its complex neuromusculature, the face is capable of realizing a highly fine-grained form of mimicry. ${ }^{17}$ Facial mimicry consists of the generally involuntary activity of facial muscles that occurs in response to seeing the same facial expressions in others. Human perceivers at all age stages spontaneously imitate facial expressions (Meltzoff and Moore, 1977, 1989; Dimberg, 1997; Doherty, 1998; Lang et al., 1993; Öhman, 2002). Even viewing static pictures of facial expressions produces rapid, covert activation of one's own facial musculature mimicking the viewed faces (Lundqvist and Dimberg, 1995; Dimberg and Thunberg, 1998).

As already noted, mimicry tends to induce an affiliative motivation to socially engage by enhancing feelings of connectedness, rapport, and cooperation. However, mimicry is likely to have an even greater influence than synchrony upon our experience of others. There is some evidence that facial mimicry influences judgments that we make about others' personalities (Blairy et al., 1999). Moreover, some researchers have speculated that facial mimicry may also contribute to social understanding by playing a central role in mindreading: namely, in the attribution of mental states to others based on their facial expressions (Lipps, 1907; Niedenthal et al., 2001; Goldman and Sripada, 2005). The suggestion is that in order to perceive and understand what type of emotion an individual is experiencing, it may first be necessary to facially mimic that state. According to one model-the reverse simulation model (Lipps, 1907; Blakemore and Decety, 2001; Goldman and Sripada, 2005)_face-based emotion recognition is

\footnotetext{
${ }^{17} \mathrm{Head}$ and body cues (facial expressions versus posture, hand gestures, patterns of movement, etc.) convey different socio-affective information (Ekman, 1965). While bodily cues convey information about the intensity or level of arousal of an emotional experience but little about the specific kind of emotion (but see de Gelder, 2009), facial expressions, in contrast, convey information about the specific kind of emotion being experienced but less about its intensity. Perception of both facial and bodily cues is thus crucial for social interaction, given that each provides different information. Nevertheless, it is the face which provides more fine-grained, emotion-specific information.
} 
a three-step process. First, an observer sees a facial expression of emotion in another person and automatically mimics this expression. Second, proprioceptive facial feedback produces traces of the emotion being mimicked in the observer. Third, the observer classifies her own attenuated emotional experience and proceeds to attribute this emotion to the observed face. This simulation heuristic need not be something the observer deliberately initiates or is even aware of; rather, it is rapid, covert, and automatic, occurring at a sub-threshold level.

There are multiple lines of evidence that appear to support this thesis and affirm the facilitative role of facial mimicry in mindreading. ${ }^{18}$ Step one is supported by the previously-cited evidence concerning our tendency to covertly mimic the facial expressions of those we observe. Steps two and three receive independent support from other strands of research.

For example, a number of studies have found that deficits in the production of a particular emotional experience and deficits in the face-based recognition of that same emotion in others reliably co-occur (Goldman and Sripada, 2005). Adolphs et al. (1994) found that an individual who suffered from bilateral destruction of her amygdalae-widely recognized to play a central role in mediating fear-showed severe impairment in face-based recognition of fear. Importantly, this individual also showed a severe impairment in her experience of fear (Damasio, 1999, p. 66), along with an abnormality in acquiring or facially expressing conditioned emotion responses (e.g., expressions of fear) (Bechara et al., 1995). Similar effects have been found with disgust and anger. ${ }^{19}$ Numerous other studies have found that individuals with disorders of emotional experience-for example, schizophrenia or major depressive disorder, both of which involve flattened affect, anhedonia, and, crucially, diminished facial expressivityprocess emotional information abnormally (see Atkinson, 2007, pp. 363-366 for a review). In these cases, a deficit in our ability to facially express a specific emotion-and thus experience traces of that emotion (see below) - may impede our ability to see that same emotion in others. ${ }^{20}$

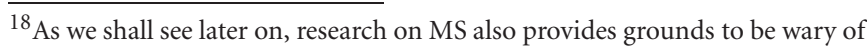
the reverse simulation model.

${ }^{19} \mathrm{An}$ individual suffering from damage to his anterior insula and basal ganglia-and whose overall score for disgust on a questionnaire was significantly lower than that of controls (even though his anger and fear scores did not differ from control's mean scores)—showed selective and significant impairment in face-based disgust recognition (Calder et al., 2000b; see also Adolphs et al., 2003). Another study found that the administration of sulpride, an antipsychotic drug that reduces aggression by blocking dopamine receptors, impaired otherwise healthy participant's recognition of facial displays of anger but no other emotions (Lawrence et al., 2002).

${ }^{20}$ It may be objected that, in these latter cases, it's not, as this gloss suggests, the lack of peripheral facial responses that's the real problem-peripheral facial nerves are in fact normal in these patients-but rather a central deficit in fear representation (or disgust or anger, for example). So, they don't shed much light on the role of facial mimicry in facilitating emotion comprehension; rather, they indicate the centrality of representation. However, this objection presupposes a linear causal pathway running from representations to facial exertions; the former is antecedent to the latter. But it may be, rather, that since these individuals are unable to produce any traces of the emotion within their own system, the requisite facial exertions "fail to arouse the appropriate neural activity for emotion production" (Goldman and Sripada, 2005, p. 204). In other words, the causal pathway may be bi-directional. A sizeable body of
}

Another line of support comes by way of the facial feedback hypothesis, according to which proprioceptive feedback from facial expressions is either necessary or sufficient for emotional experience (Izard, 1971; Laird, 2007). Simply mimicking the facial displays of happiness - smiling broadly, raising one's eyebrowsmay be enough to induce the experience of that state (Adelmann and Zajonc, 1989; Soussignan, 2002) and its associated facial EMG and patterns of autonomic arousal (Hess et al., 1992). Conversely, many studies indicate that the inhibition of bodily expression-particularly facial expression-diminishes the phenomenal intensity of experienced emotion (Darwin, 1872; see also Laird, 2007 and Niedenthal, 2007) and, more pertinent for our concerns, interferes with processing of emotional information, including our response to others' face-based emotional cues (Niedenthal et al., 2005; Niedenthal, 2007). For example, individuals who have voluntarily undergone Botox injections report both a decrease in the experiential intensity of certain emotions (Davis et al., 2010) as well as increased difficulty in processing emotional language that refers to facial expressions requiring the paralyzed facial muscles (Havas et al., 2010).

A final line of supporting evidence concerns findings related to the so-called mirror system. Within the mirror system, internal action representations are activated both in the production and the observation of an action (reaching for a cup, swinging a baseball bat, etc.). When one observes a specific action-type, neurons in the premotor cortex and posterior parietal cortex fire as if one were performing that same action-type oneself (Gallese et al., 1996; Rizolatti et al., 1996; Iacoboni et al., 2001). More pointedly, there is evidence that the mirror system may be operative during the observation of facial expressions. For example, an fMRI study by Carr et al. (2003) found that a similar network of brain areas (including the premotor cortex) were active both when a subject imitated and passively observed an emotion-expressive face. Other studies have found similar results (Leslie et al., 2004; Dapretto et al., 2005). Together, they suggest that the activation of mirror neurons when observing face-based emotion expressions may code equivalence between self and other, which allows for an empathic understanding of another's emotional cues. Mirror neuron activity may thus be another layer of simulation sub-serving facial mimicry.

In summary, both movement synchrony and mimicry are two basic forms of behavioral coupling that generate rapport and motivate us to interact with others. Beyond this, mimicryespecially facial mimicry - may introduce a critical mindreading dimension that is crucial in facilitating rudimentary social understanding (e.g., emotion detection). In various ways, these studies further affirm that the animate face, expressively coupled to other animate faces, is the lynchpin of social understanding. It, therefore, seems reasonable to expect that individuals with MS, deprived of this lynchpin, would face various difficulties in

evidence-some of which is mentioned in the following paragraph-indicates that facial movements precede emotion experience (see Goldman and Sripada, 2005, pp. 205-206; Atkinson, 2007 pp. 369-374); other studies posit a link between somatosensory impairment and face-based emotion recognition (see, for example, Adolphs et al., 2000). We are grateful to one of the reviewers for pressing us here. 
understanding others; certainly SI predicts this outcome. Let us now take a closer look at the social difficulties that have been reported in people with MS.

\section{THE EFFECTS OF IMPAIRED SYNCHRONIZATION AND MIMICRY UPON SOCIAL EXPERIENCE IN MS}

Given the role of synchronization and facial mimicry in sustaining rapport, it is no surprise that individuals with MS tend to exhibit more traits of inhibition, introversion, and feelings of social inadequacy and inferiority than a matched control group (Briegel, 2007). Moreover, the disruption of movement synchrony in the faces of interacting partners could also impede the development of movement synchrony in other parts of the body-if, for example, the non-MS interactant is put off by or misinterprets the lack of facial synchrony. If synchrony facilitates the coordination of movements within joint actions by increasing partners' attention to one another's movements and by making both partners more predictable to each other, then a disruption in synchrony could lead to difficulties in coordination within joint actions for groups in which one or more members has MS. This could be one reason for the general difficulties with social interactions that individuals with MS often report (Bogart and Matsumoto, 2010b). In addition, the evidence that facial mimicry influences our perception of others' personalities (Blairy et al., 1999) might partially explain why individuals with facial impoverishment are often perceived as unfriendly, depressed, disinterested, or unintelligent (Lyons et al., 2004; Tickle-Degnen and Lyons, 2004), making others less likely to pursue friendships with them (Hemmesch et al., 2009).

It must be emphasized, however, that this is not true of all individuals with MS. We will look more carefully at individual differences in compensatory strategies momentarily. First, however, we would like to consider a different issue separate from the question of how non-MS interactants shape the dyadic encounter. This issue has to do with MS side of the dyad: namely, face-based emotion recognition in people with MS. Many of the studies canvassed in section "Gestural coupling: synchrony and mimicry," along with the reverse simulation model of emotion recognition, suggest that individuals with deficits in producing, experiencing or expressing an emotion may also suffer from a deficit in the face-based recognition of that same emotion when they see it in others (e.g., Adolphs et al., 1994, 2000, 2003; Calder et al., 2000a; Goldman and Sripada, 2005). To reiterate, the idea is that face-based emotion recognition requires one to facially mimic the observed state; this mimicry may then generate an attenuated emotion experience within oneself that is used to classify the observed emotion in another. Given their complete lack of facial expressivity-as well as reports that MS can lead to a reduction in emotional experience-people with MS appear to be physiologically precluded from engaging in either part of this process (i.e., the mimicry or the production/experience of the emotion). They are, therefore, an ideal group to test this hypothesis.

Clearly people with MS cannot facially express emotion. Based upon reports from some with MS, it also appears that this inability to facially express emotions correlates with a deficit in producing and experiencing certain emotions (Cole, 2010). For example, James, a priest in his fifties with MS, writes, "I sort of think happy or think sad, not really saying, or recognizing, actually feeling happy or sad ... I've often thought of myself as a spectator rather than a participant" (Cole, 1999, p. 308). Other reports express a similar sentiment. Since people with MS cannot produce facial expressions - and since basic emotions appear to have innate, cross-cultural facial signatures (Ekman, 1993; Matsumoto and Willingham, 2009) - it is not surprising that they report a deficit in emotional experience, if the embodied expression of an emotion (along with its social sharing) is indeed necessary for its being experienced (Niedenthal, 2007; Cole, 2010, p. 667; see also Krueger, 2011, forthcoming). ${ }^{21}$

These reports are all the more reason to expect that people with MS also have a deficit in mindreading (i.e., processing facial expressions of emotion). Again, the reverse simulation modelwhich, in emphasizing the centrality of facial coupling, can be thought of as endorsing SI-certainly predicts this outcome. But things are not that simple. There have been few studies of face-based emotion recognition in people with facial paralysis (Giannini et al., 1984; Calder et al., 2000a; Keillor et al., 2002). While these studies offer some evidence that people with MS exhibit a deficit in emotion recognition, they suffer from small sample sizes; moreover, they offer conflicting results. Giannini et al. (1984), for example, report that a woman of normal intelligence with MS was completely unable to perform a facial recognition task. However, Calder et al. (2000)-based upon a study of three participants with MS and a control group of 40 normal participants - found that one participant with MS was unimpaired in an expression recognition task, one showed mild deficits, and one was significantly impaired. A woman with temporary bilateral facial paralysis (due to Guillain-Barre syndrome) in Keillor et al. (2002) showed no impairment.

Conducting a study on the internet, Bogart and Matsumoto (2010a) were able to achieve a sample size of 37 people with MS, paired with 37 age and gender matched controls. Participants viewed a total of 42 photos from Matsumoto and Ekman's (2006) Multi-Ethnic Facial Expression set. They indicated which emotion was being expressed by selecting from a list of response choices including the seven universally-produced emotions (Ekman and Friesen, 1975; Matsumoto and Willingham, 2009), "neutral," and "other." Participants also completed a Facial Expression Communication Questionnaire (FECQ) to assess their self-reported ability to facially communicate the seven universal emotions. The result was that people with MS, despite an inability to enact facial coupling (i.e., mimicry) and experience proprioceptive facial feedback (and perhaps attenuated emotional experience), did not differ from the matched control group or normative data in their ability to accurately recognize facial expressions (Bogart and Matsumoto, 2010b, p. 247).

What are we to make of these findings? One immediate consequence is that they appear to challenge the predictions of the

\footnotetext{
${ }^{21}$ To be clear, many emotions may require a more robustly embodied expression (i.e., not simply a facial expression) to be experienced. And since people with MS often report feeling distanced from their body as a whole, particularly in childhood development, their expressive deficit may encompass not just their face but rather the whole overt bodily expressive form of particular emotions (see Cole and Spalding, 2009, pp. 41-56, 196-202).
} 
reverse simulation model and the facial feedback hypothesis. They also appear to challenge SI more generally (more on that in a moment). While much evidence suggests that people spontaneously mimic the facial expressions they observe in others, it is not clear that mimicry is required to see these emotions as such (Gump and Kulik, 1997; Blairy et al., 1999). Rather, the provisional conclusion to draw is that facial mimicry (in those capable of it) provides additional motor information regarding the expression to decode-and thus creates a certain facilitative effect within the face-to-face dynamics of real-time interactionbut that mimicry is not necessary for emotion recognition. At least a certain form of social understanding (perceptually decoding emotions) can proceed independently of mimicry.

In response, the proponent of the reverse simulation model might argue that the mirror system (located in the frontal and parietal lobes) remains intact in people with MS; their neural disturbance is relatively peripheral, involving the sixth and seventh cranial nerves. So, the mirror system might be operative-and a neural form of mimicry present-even if there is no facial mimicry to reflect it. The necessary feedback may thus derive from activation of motor plans in premotor and/or parietal areas rather than from the facial musculature. ${ }^{22}$ This is possible, and would indeed be worth investigating in an imaging study. One reason to be skeptical, however, is that peripheral neural disturbances have higher-level effects at the cortical level. For example, there are reports that early peripheral blindness leads to changes in the visually deprived cortex (Neville and Bavelier, 2000, pp. 89-90). Other research indicates that cortical reorganization in individuals following finger amputation can occur as quickly as ten days after their operation (Weiss et al., 2000). On the other hand, Gazzola et al. (2007) reported finding that two aplasics subjects (born without arms or hands) had more or less normal levels of activation in the putative mirror system while observing hand actions. This may suggest that neural circuits underlying action representations in premotor cortex are unaffected by the peripheral differences in these subjects' bodies. Interestingly, however, when observing some hand actions, the aplasic subjects showed increased activation in areas that were also recruited when they themselves used one of their feet to perform an equivalent action, thus suggesting that their development of a compensatory action repertoire had an influence upon the neural processes underlying action recognition. ${ }^{23}$ In sum, it must be regarded as an open question whether peripheral neural deficits in people with MS have or have not resulted in higher-level deficits.

Another response open to the proponent of the reverse simulation model is to suggest that people with MS develop various compensatory strategies to replace their lack of facial expressiveness; we ought to therefore look to these cases with caution and hesitate to generalize their results (Goldman and Sripada, 2005, p. 206). Since people with MS have lived with their condition

\footnotetext{
${ }^{22}$ Note, however, that this response entails abandonment of the facial feedback hypothesis, which is committed to the claim that it is feedback from the facial musculature that informs face-based emotion recognition.

${ }^{23}$ As one reviewer suggested, a thorough comparison of aplasic subjects with individuals with MS could prove very fruitful-in particular with respect to the effects of compensatory behaviors that they adopt.
}

their entire lives, it is possible that with time and experience they have developed other means to achieve social understanding. Moreover, it is also reasonable to assume that people with congenital conditions such as MS are better adapted to their condition compared to those with an acquired disability (Smart, 2008). For these reasons, it would indeed be hasty to draw far-reaching conclusions about the role of mimicry in face-based emotion recognition among individuals without MS.

We acknowledge the persuasive force of this response and indeed think that it points in an important direction. If, as MI claims, social cognition is a diverse collection of strategies and practices, it is likely that alternative strategies are available for those with MS that compensate for their lack of facial mimicry. Indeed, there is evidence that individuals do indeed avail themselves of such alternative strategies and, even more importantly, that the use of such strategies is correlated with self-esteem, comfort in social interactions, and overall well-being. In the following section, we look more carefully at these strategies.

For now, we only want to note that although these findings do not justify any definitive conclusions about the reverse simulation model or about the facial feedback hypothesis, they do put pressure on SI. This is because individuals with MS lack a crucial component needed for interaction: facial coupling. With their absence of facial mobility, they lack what SI considers to be either an essential enabling condition or a constitutive condition for social understanding (understood, as SI would have it, as behavioral coupling). For not only do they lack expression now; crucially, they've never had it and thus have always lacked this critical enabling condition. From the perspective of SI, then, this inability to interact with others at the level of facial coupling should also impair their ability to understand facial expressions of emotions. As one proponent of SI puts it in a recent paper: "[W]e may experience another's feelings and intentions directly, but direct perception builds on something, namely on skillful interaction with others. In other words, social interaction is [...] constitutive of the process of social understanding and also of direct social perception" (de Jaegher, 2009, p. 538). Yet at least when it comes to emotions, people with MS can, as we've seen, both detect and respond to another's expressions. In short, they realize social understanding in the absence of this central coupling component. However, this is not the only reason to think that MS challenges the predictions of SI. We consider some further reasons now and discuss how they appear to lend credence to MI.

\section{COMPENSATORY STRATEGIES}

Since they lack the ability to enact facial mimicry, a central form of behavioral coupling, people with MS employ various compensatory strategies to navigate their social world. To help further evaluate SI and MI, we distinguish two kinds of compensatory strategies: de-coupled and coupled. We argue that both strategies put pressure on SI, although for different reasons. De-coupled strategies do so because they compensate for the disruption of facial coupling by utilizing explicitly cognitive strategies that are not inherently interactive-at least in the sense SI requires. Coupled strategies, in contrast, initiate alternative forms of interactive coupling. This is not in itself a problem for SI. Rather, the problem is that these alternative strategies are deliberately and 
explicitly adopted, and thereby demonstrate the importance of individual cognitive processes and capacities (top-down control, deliberate reasoning, conscious observation, and integration of contextual information, etc.) in enabling coupling. We examine these two strategies in turn.

\section{DE-COUPLED STRATEGIES}

People with MS report that a very common-perhaps centralstrategy they employ to get along socially is an individualistic cognitive strategy: explicit mentalizing. They often report consciously scrutinizing another's face or actions, reflecting on the data present therein, and adopting an observational or spectatorial perspective to sort out what it is others are up to. They may even adopt an explicit mentalizing perspective when monitoring their own expressions.

For example, children with MS tend to be avid readers. Many report learning about emotions and sociality from studying the narratives of characters in books (Cole and Spalding, 2009). Another man describes the process of falling in love with his wife this way: "I was initially thinking I was in love with her. It was some time later when I realized that I really felt in love" (Quoted in Cole and Spalding, 2009, p. 70). This mentalizing strategyalong with other explicit strategies like rote learning of gestures by watching others or deliberate verbal disclosure of emotionssuggests that people with MS often rely upon explicit cognitive strategies to compensate for their lack of facial expressiveness (Bogart et al., 2012).

This mentalizing strategy signals trouble for SI. The noninteractive character of this spectatorial stance is offered by defenders of SI as a reason to question false belief tests as the benchmark of social cognitive competence. SI proponents claim that these tests put children in the un-natural position of being passive onlookers, not on-line interactants (Gallagher, 2001, p. 99; Hutto, 2004, p. 549; Ratcliffe, 2007, p. 54). Since only children of roughly 4.5 years or more can pass explicit verbal false belief tests, ${ }^{24}$ this explicitly mentalistic orientation, SI defenders claim, overlooks the repertoire of embodied capacities in place at birth which appears to support rudimentary, non-mentalistic forms of social understanding operative long before we are able to pass false belief tests. More simply, the passive theorizing required by false belief tests is not a kind of genuine interaction, according to the SI proponent; or minimally, it requires the presence of a more fundamental form of embodied interaction that proceeds independently of explicit mentalizing. The latter is thus a derivative form of non-interactive social understanding.

However, in people with MS who lack a crucial embodied component, explicit mentalizing sometimes comes to the forefront as a compensatory non-interactive (i.e., de-coupled) strategy yielding effective social understanding. So, it simply cannot be that interaction - which, according to SI, is distinct from spectatorial mentalizing strategies - is constitutive [i.e., a necessary "here and now" component (de Jaegher et al., 2010)] of social understanding. In response, the SI proponent can argue that this explicit mentalizing is itself a kind of interaction. However, this move both (1) appears inconsistent with SI's critique of the mentalistic

\footnotetext{
${ }^{24}$ See Doherty, 2009 for a review of these studies.
}

orientation of the false belief test (as well as its critique of the Theory of Mind paradigm more generally), and (2) risks stretching the definition of "interaction" so thinly that it becomes unclear what is genuinely distinctive about SI.

\section{COUPLED STRATEGIES}

Not all strategies are explicitly mentalistic. Some of the strategies employed by people with MS involve compensatory expressive gestures. For example, individuals with MS report using eye contact to display confidence and exaggerated prosody, body language, and verbal disclosure to express emotion (Meyerson, 2001; Bogart and Matsumoto, 2010a, p. 136). Gestures may become exaggerated to replace facial animation; prosody and posture can likewise be recruited, as can spatial proximity to others (Krueger, 2011). As one man with MS writes, "The tone, the volume, the timbre of the voice, and bodily language, I use to supplement in ways that my face can't provide ... I have a whole repertoire of laughs that I use to respond to different situations" (Bogart et al., 2012). A recent study appears to confirm that people with congenital facial paralysis employ increased compensatory expressive behavior (Bogart et al., 2012; see also Chaimov et al., 2011).

An intriguing consequence is that the adoption of compensatory expressive gestures may initiate alternative forms of behavioral coupling. Since social interaction is both reciprocal and synchronous (i.e., it includes behavioral matching), it is likely that these compensatory strategies are mirrored in interaction partners, giving people with MS access to non-face-based informational channels (voice, posture, gesture, spatial proximity, etc.) from which they can glean information about their partner's emotional status. In short, the recruitment of compensatory expressive strategies may cause new signals to emerge on both sides of the interactive dyad that take the place of face-based cues. Although there is no direct evidence to support this proposal at the moment, we submit that the extensive body of research on mimicry and synchronization canvassed above provides sufficient indirect support to lend it a high degree of plausibility. At any rate, the proposal points out an intriguing direction to be investigated by future research.

The behavioral strategies presented in this section, in contrast to explicit mentalizing, present alternative ways of sustaining engagement within interaction. As such, they do not immediately appear to challenge SI. The important point for our purposes is that, although they are coupled strategies, they are nevertheless deliberately and explicitly adopted, and thereby demonstrate the importance of individual cognitive processes in enabling at least some forms of interactive coupling. For example, one 40-yearold-woman with MS writes: "All my gesture is voluntary, even now aged 46. Everything I do, I think about ... All the things I am doing, whether turning my head or moving my hands, is all self-taught. I learnt from observation as a child" (Quoted in Cole and Spalding, 2009, p. 190). Another woman describes learning to bodily express emotions by deliberately watching locals whilst on holiday in Spain and then intentionally adopting their gestural patterns upon her return to the UK (Cole and Spalding, 2009, pp. 154-155).

Again, our claim is not that SI excludes the possibility that explicit compensatory strategies may initiate alternative forms of 
coupling. Rather, the problem for SI, as we see it, is that it does not predict that this would occur. And this is no accident. Insofar as SI regards coupling processes as alternatives to individual cognitive processes (which, once again, for SI may marginalize individual cognition or even render it superfluous), it is conceptualized in a way that is in tension with integrative proposals-such as the version of MI we are defending-acknowledging that both coupled and de-coupled strategies can co-exist and work together in helping us navigate the complexities of our social world.

\section{GENERALIZING THE FINDINGS FROM THE CASE STUDY}

In the previous section, we argued that compensatory coupled strategies (increased eye contact, exaggerated gestures and prosody, etc.) are often explicitly and deliberately adopted by people with MS, and that they are, therefore, dependent upon integration with higher-level individual cognitive processes. We also suggested that this is no anomaly. Rather, it exemplifies MI's more general conception of fine-grained coordination of higherlevel individual cognition and behavioral coupling. To motivate this latter claim about the generalizability of the findings discussed here, let us close with a brief sidelong glance toward the broader research context in which we would like to embed this case study.

There is ample evidence of top-down effects upon relatively automatic, unconscious bodily processes in social interaction. It has been shown, for example, that empathetic pain responses, as measured by activation in ACC, are modulated by numerous contextual factors such as whether or not one believes the person experiencing the pain deserves it (de Vignemont and Singer, 2006). It has also been shown that sub-threshold behavioral mimicry, as assessed by co-representation tasks, is modulated by perspective-taking (Müller et al., 2011).

Additionally, consider research concerning the situationdependence of mimicry. Several studies have found that mimicry is modulated by prior attitudes of the observer or by group membership. For example, individuals observed watching video excerpts of politicians were more likely to facially mimic if they shared the politician's views than if they did not (McHugo et al., 1991; Bourgeois and Hess, 2008). Interactants were also found to preferentially mimic certain facial displays depending upon the social context (Hess and Bourgeois, 2010). Finally, it has been show that we are more likely to imitate people with high statusan efficacious strategy given that imitation tends to increase rapport (Cheng and Chartrand, 2003).

There are also reasons to think that mimicry is not only modulated but sometimes actively suppressed by top-down control (Brass et al., 2005). Again, mimicry increases rapport. However, there are surely occasions where rapport gets in the way of performing a task - it may, for example, prevent one from suspecting others of lying or cheating, and thus detract from one's performance when the task is to detect liars or cheaters (cf. Stel et al., 2009). And there is some empirical support for the notion that people indeed suppress mimicry in a way that is sensitive to such considerations. Lanzetta and Englis (1989) found mimicry in a cooperative context (e.g., teammates in a game) but countermimicry in a competitive context (e.g., opponents in a game) (see also Hess, 1998).
These results suggest that mimicry is not as automatic and reflex-like as is generally assumed. Rather, it is embedded in broader networks of social information that comes from various channels: information given not just by another's face but by their body (posture, gesture), voice (prosody, language, etc.), and spatial proximity, as well as background information about their personality, goals and interests. We have been arguing that this is typical for the bodily and interactive processes that are recruited in social interaction, and that our case study provides additional supporting evidence for this general view.

Another intriguing possibility, which we hope can be explored in future research, is to consider whether some of the patterns we have observed and some of the strategies we have documented may be valid for various other disorders besides MS. One obvious comparison would be to individuals with facial impoverishment due to Parkinson's disease. Do these individuals also employ some of the same kinds of compensatory strategies as individual with MS? If so, what effects does that have upon coupling processes within social interactions? What differences does it make that their condition is an acquired rather than a congenital one? Another potentially interesting comparison would be to investigate individuals with Autism Spectrum Disorder (ASD), some of whom likely employ de-coupled strategies to compensate for their difficulties in social interactions. Indeed, it has been suggested that autists are unable to depend upon intuitive, flexible processes (e.g., implicit mentalizing, implicit understanding of social codes and conventions) that characterize much of everyday social cognition in normal, healthy subjects, and that they often favor deliberate rule-based reasoning (perhaps a kind of highly "theorydriven" mentalizing) as an alternative strategy (Hermelin and O'Connor, 1985; Bowler, 1992; Sacks, 1995; Zahavi and Parnas, 2003; Hobson et al., 2006; Williams and Happé, 2010; Lehnhardt et al., 2011). This proposal draws support from studies that have found evidence that performance on emotion recognition tasks is uniquely supported by verbal intelligence among individuals with autism (e.g., Grossman et al., 2000). Intriguingly, some researchers have even reported that individuals with ASD are more likely than control subjects to imitate observed facial expressions when asked to categorize them, suggesting that they may employ an explicit simulation routine as a compensatory strategy (Gepner et al., 2001; Wright, 2008). It is also interesting in this context to note that, although individuals with ASD are less likely to spontaneously gaze-follow (Klin et al., 2002) and scan faces (Osterling et al., 2002), they can do so if explicitly instructed and indeed improve at social cognition tasks as a result (Weeks and Hobson, 1992).

And yet, although compensatory strategies may enable autists to perform well on some experimental tasks, this is in contrast to the manifest difficulties that autists typically have in their social lives (Hobson et al., 2006; Williams and Happé, 2010). Unfortunately, such strategies may not apply well to real online social situations which typically require quick, flexible, and context-sensitive reasoning, and where deliberate de-coupled reasoning can disrupt the flow of interaction, and disrupt autists' online self-monitoring as well. For individuals with MS, however, the situation may be importantly different since there is no reason to expect them to have difficulties detecting or responding 
to social contingency or with quick, flexible and context-sensitive reasoning. As a result, although they lack one important but replaceable enabler of behavioral coupling, they may well have no problems with coupling per se, whereas individuals with ASD may (cf. Timmermans et al., in press). Thus, we would conjecture that the compensatory strategies employed by individuals with MS are more likely than those employed by individuals with ASD to lead to alternative forms of coupling.

\section{CONCLUSIONS: THE PLURAL PRACTICE OF SOCIAL COGNITION}

We have argued that SI appears to both make too strong a claim and adopt too narrow a focus when it comes to thinking about how we realize social understanding. Perhaps the most substantive lesson from MS cases, we suggest, is that they affirm the idea that social cognition is a heterogeneous group of processes, strategies, and practices that collectively enable us to negotiate the social world. We earlier christened this ecumenical approach MI. Again, the core of MI is the idea that interaction may offer resources and afford access to information that can complement, if not necessarily replace, the resources and information available to individual processes. In other words, MI maintains that the bodily processes that enable coupling in social interactions can-along with information-processing in the brain-jointly constitute cognition and emotion. Contra SI, it thus denies that coupling itself is the exclusive locus of social understanding. Rather, coupling functions alongside and indeed often together with various individualistic processes and strategies.

Apart from providing a better interpretation of existing facts bearing upon the relationship between coupling and higher-level, more conscious and deliberate control, we think that MI also offers a promising platform for future research-particularly with respect to MS but also in social cognition research more generally. For example, as we have pointed out, MI generates the hypothesis that the compensatory strategies adopted by individuals with MS may spread to their interaction partners and thereby open up alternative informational channels (voice, posture, gesture, spatial proximity, etc.) within which coupling may occur. However, insofar as the need to learn how to compensate in these alternative ways may be a challenge for individuals

\section{REFERENCES}

Adelmann, P. K., and Zajonc, R. B. (1989). Facial efference and the experience of emotion. Annu. Rev. Psychol. 40, 249-280.

Adolphs, R. (2006). How do we know the minds of others? Domainspecificity, simulation, and enactive social cognition. Brain Res. 1079, 25-35.

Adolphs, R., Damasio, H., Tranel, D., Cooper, G., and Damasio, A. R. (2000). A role for somatosensory cortices in the visual recognition of emotion as revealed by three-dimensional lesion mapping. J. Neurosci. 20, 2683-2690.

with MS, it may cause subsequent delays in the development of social skills or cognition more generally. This is an empirical question worth investigating further (see Cole and Spalding, 2009, pp. 180-185). It could, therefore, be fruitful for future research on MS to investigate the development of gesturing and gestural coupling in MS from a developmental perspective, and to look for correlations with the development of other socialcognitive processes. Moreover, MI also raises novel questions about disruptions of coupling as such and corresponding compensatory strategies more generally. Thus, future research may investigate whether the patterns we have observed and some of the strategies we have documented may be generalizable to other conditions such as Parkinson's Disease or ASD_-and in particular, whether there are any similarities or important differences between the disruptions of coupling in MS, Parkinson's, and ASD, or between the different strategies employed to compensate for them.

In addition to potentially offering a platform for future research, MI also seems to accord with the phenomenology of everyday social experience. Surely those of us without MS also avail ourselves of diverse resources and shift fluidly among strategies in our social interactions. Sometimes, as when I encounter a stranger behaving oddly, I may adopt a more theoretical perspective and summon bits of folk psychology to sort out what it is I think he's up to. Or I might imaginatively project myself into his mental shoes and try and figure out how I might feel and act in that situation. At other times, direct perception may provide sufficient information about another's intentions and emotions without my having to summon theories or simulations. In short, the conception of gestural coupling as one tool among many others in the mature agent's social toolkit is supported by evidence from a broader research context and fits well with the phenomenology of everyday social life.

In sum, close consideration of the case of MS demonstrates the need for much more fine-grained hypotheses concerning the relationship between behavioral coupling and higher-level individual cognition than have heretofore been articulated. Additionally, it helps illustrate the explanatory merits of an integrative approach, such as MI, which takes its starting point from the heterogeneous character of social cognition and social interaction.

(Cambridge, MA: Cambridge University Press), 2, 107-131.

Apperly, I., and Butterfill, S. (2009). Do humans have two systems for tracking beliefs and belief-like states? Psychol. Rev. 116, 953-970.

Atkinson, A. P. (2007). "Face processing and empathy," in Empathy in Mental Illness, eds T. F. D. Farrow and P. W. R. Woodruff (Cambridge, MA: Cambridge University Press), 360-385.

Auvray, M., Lenay, C., and Stewart, J. (2009). Perceptual interactions in a minimalist virtual environment. New Ideas Psychol. 27, 32-47.

van Baaren, R. B., Rob, W., Holland, K. K., and Ad van, K. (2004). Mimicry and prosocial behavior. Psychol. Sci. 15, 71-74.

Baillargeon, R., Scott, R. M., and He, Z. (2010). False-belief understanding in infants. Trends Cogn. Sci. 14, 110-118.

Bechara, A. D., Tranel, H., Damasio, R. A., Rockland, C., and Damasio, A. R. (1995). Double dissociation of conditioning and declarative knowledge relative to the amygdala and hippocampus in humans. Science 269, 1115-1118.

Bennett, M., Schatz, M., Rockwood, H., and Wiesenfeld, K. (2002). Huygens's clocks. Proc. R. Soc. Lond. A 458, 563-579. 
Bernieri, F. J. (1988). Coordinated movement and rapport in teacherstudent interactions. J. Nonverbal Behav. 12, 120-138.

Bernieri, F. J., and Rosenthal, R. (1991). "Interpersonal coordination: behavior matching and interactional synchrony," in Fundamentals of Nonverbal Behavior, eds R. S. Feldman and B. Rime (Cambridge, MA: Cambridge University Press), 401-432.

Berry, D. S., and McArthur, L. Z. (1986). Perceiving character in faces: the impact of age-related craniofacial changes on social perception. Psychol. Bull. 100, 3.

Blairy, S., Herrera, P., and Hess, U. (1999). Mimicry and the judgment of emotional facial expressions. $J$. Nonverbal Behav. 23, 5-41.

Blakemore, S. J., and Decety, J. (2001). From the perception of action to the understanding of intention. Nat. Rev. Neurosci. 2, 561-567.

Bogart, K., and Matsumoto, D. (2010a). Facial mimicry is not necessary to recognize emotion: facial expression recognition by people with Moebius syndrome. Soc. Neurosci. 5, 241-251.

Bogart, K., and Matsumoto, D. (2010b). Living with Moebius Syndrome: adjustment, social competence, and satisfaction with life. Cleft Palate-Craniofac. J. 47, 134-142.

Bogart, K. R., Tickle-Degnen, L., and Ambady, N. (2012). Compensatory expressive behavior for facial paralysis: adaptation to congenital or acquired disability. Rehabil. Psychol. 57, 43-51.

Bourgeois, P., and Hess, U. (2008). The impact of social context on mimicry. Biol. Psychol. 77, 343-352.

Bowler, D. M. (1992). 'Theory of mind' in Asperger's syndrome. J. Child Psychol. Psychiatry 33, 877-893.

Brass, M., Derrfuss, J., and von Cramon, D. Y. (2005). The inhibition of imitative and overlearned responses: a functional double dissociation. Neuropsychologia 43, 89-98.

Briegel, W. (2006). Neuropsychiatric findings of Mobius sequence: a review. Clin. Gen. 70, 91-97.

Briegel, W. (2007). Psychopathology and personality aspects of adults with Moebius sequence. Clin. Gen. 71, 376-377.

Buck, J., and Buck, E. (1976). Synchronous fireflies. Sci. Am. 234, 74-85.

Bushnell, I. W. R. (2001). Mother's face recognition in newborn infants: learning and memory. Infant Child Dev. 10, 67-74.
Calder, A. J., Keane, J., Cole, J., Campbell, R., and Young, A. W. (2000a). Facial expression recognition by people with Mobius Syndrome. Cogn. Neuropsychol. 17, 73-87.

Calder, A. J., Jill, K., Facundo, M., Nagui, A., and Young, A. W. (2000b). Impaired recognition and experience of disgust following brain injury. Nat. Neurosci. 3, 1077-1078.

Carr, L., Iacoboni, M., Dubeau, M. C., Mazziotta, J. C., and Lenzi, G. L. (2003). Neural mechanisms of empathy in humans: a relay from neural systems for imitation to limbic areas. Proc. Natl. Acad. Sci. U.S.A. 100, 5497.

Chaimov, K., Hernandez, S. KokEnnen, S., Krull, E., and Rives Bogart, K. (2011). Factors Impacting Social Interaction in Moebius Syndrome. Norwood, MA: Presented at the Massachussetts Association for Occupational Therapy Conference.

Chartrand, T., and Bargh, J. A. (1999). The chameleon effect: the perception-behavior link and social interaction. J. Pers. Soc. Psychol. 76, 893-910.

Chen, Y. P., Ehlers, A., Clark, D. M., and Mansell, W. (2002). Patients with generalized social phobia direct their attention away from faces. Behav. Res. Ther. 40, 677-687.

Cheng, C. M., and Chartrand, T. L. (2003). Self-monitoring without awareness: using mimicry as a nonconscious affiliation strategy. J. Pers. Soc. Psychol. 85, 1170-1179.

Cooke Macgregor, F. (1990). Facial disfigurement: problems and management of social interaction and implications for mental health. Aesthetic Plast. Surg. 14, 249-257.

Cole, J. (1999). "On "Being Faceless": selfhood and facial embodiment," in Models of the Self, eds S. Gallagher and J. Shear (Charlottesville, VA: Imprint Academic), 301-318.

Cole, J. (2010). "Agency with impairments of movement," in Handbook of Phenomenology and Cognitive Science, eds D. Schmicking and S. Gallagher (Dordrecht: Springer), 655-670.

Cole, J., and Spalding, H. (2009). The Invisible Smile: Living without Facial Expression. Oxford: Oxford University Press.

Condon, W. S. (1982). "Cultural microrhythms," in Interaction Rythms: Periodicity in Communicative Behavior, ed M. Davis (New York, NY: Human Sciences), 53-77.

Damasio, A. (1999). The Feeling of What Happens: Body and Emotion in the Making of Consciousness. New York, NY: Harcourt Brace.

Dapretto, M., Davies, M. S., Pfeifer, J. H., Scott, A. A., Sigman, M., Bookheimer, S. Y., and Iacoboni, M. (2005). Understanding emotions in others: mirror neuron dysfunction in children with autism spectrum disorders. Nat. Neurosci. 9, 28-30.

Darwin, C. (1872). The Expression of the Emotions in Man and Animals. Chicago, IL: University of Chicago Press.

Davis, J. I., Senghas, A., Brandt, F., and Ochsner, K. N. (2010). The effects of BOTOX injections on emotional experience. Emotion 10, 433-440.

de Gelder, B. (2009). Why bodies? Twelve reasons for including bodily expressions in affective neuroscience. Philos. Trans. R. Soc. Lond. Biol. Sci. 364, 3475-3484.

de Rugy, A., Salesse, R., Oullier, O., and Temprado, J. J. (2006). A neuro-mechanical model for interpersonal coordination. Biol. Cybern. 94, 427-443.

de Vignemont, F., and Singer, T. (2006). The empathic brain: how, when and why? Trends Cogn. Sci. 10, 535-541.

Dimberg, U. (1997). Facial reactions: rapidly evoked emotional responses. J. Psycholinguist. Res. 11, 115-123.

Dimberg, U., and Thunberg, M. (1998). Rapid facial reactions to emotional facial expressions. Scand. J. Psychol. 39, 39-45.

Di Paolo, E. (2009). Editorial: the social and enactive mind. Phenomenol. Cogn. Sci. 8, 409-415.

Di Paolo, E. A., Rohde, M., and lizuka, H. (2008). Sensitivity to social contingency or stability of interaction? Modelling the dynamics of perceptual crossing. New Ideas Psychol. 26, 278-294.

Doherty, R. W. (1998). Emotional contagion and social judgment. Motiv. Emot. 22, 187-209.

Doherty, M. J. (2009). Theory of Mind: How Children Understand Others' Thoughts and Feelings. Hove: Psychology Press.

Ekman, P., and Friesen, W. V. (1975). Unmasking the Face: A Guide to Recognizing Emotions from Facial Clues. New Jersey, NJ: Prentice Hall.

Froese, T., and Di Paolo, E. A. (2010). Modelling social interaction as perceptual crossing: an investigation into the dynamics of the interaction process. Connect. Sci. $22,43$.

Fuchs, T., and de Jaegher, H. (2009). Enactive intersubjectivity: participatory sense-making and mutual incorporation. Phenomenol. Cogn. Sci. 8, 465-486.

Gallagher, S. (2001). "The practice of mind: theory, simulation, or primary interaction?" J. Conscious. Stud. 8, 83-108.

Gallagher, S. (2008). Inference or interaction: social cognition without precursors. Philos. Explor. Int. J. Philos. Mind Action 11, 163-174.

Gallese, V. (2001). The "shared manifold" hypothesis: from mirror neurons to empathy. J. Conscious. Stud. 8, 33-50.

Gallese, V., Fadiga, L., Fogassi, L., and Rizzolatti, G. (1996). Action recognition in the premotor cortex. Brain 119, 593-609.

Gazzola, V., van der Worp, H., Mulder, T., Wicker, B., Rizzolatti, G., and Keysers, C. (2007). Aplasics born without hands mirror the goals of hand actions with their feet. Curr Biol. 17, 1235-1240.

Gepner, B., Deruelle, C., and Grynfeltt, S. (2001). Motion and emotion: novel approach to the study of face processing by young autistic children. J. Child Psychol. Psychiatry Allied Discip. 28, 137-151.

Gergely, G., and Watson, J. S. (1996). The social biofeedback theory of parental affect-mirroring: the development of emotional selfawareness and self-control in infancy. Int. J. Psychoanal. 77 (Pt 6), 1181-1212.

Gergely, G., and Watson, J. D. (1999). "Infant's sensitivity to imperfect contingency in social interaction," in Early Social Cognition, ed P. Rochat (Mahwah, NJ: Erlbaum), 101-136.

Giannini, A. J. D., Tamulonis, M. C. Giannini, R., Loiselle, H., and Spirtos, G. (1984). Defective response to social cues in Möbius' syndrome. J. Nerv. Ment. Dis. 172, 174-175.

Goldman, A. (2006). Simulating minds: The Philosophy, Psychology, and Neuroscience of Mindreading. Oxford: Oxford University Press.

Goldman, A. I., and Sripada, C. S. (2005). Simulationist models of face-based emotion recognition. Cognition 94, 193-213.

Gopnik, A., and Wellman, H. M. (1992). Why the child's theory of mind really is a theory. Mind Lang. 7, 145-171

Gordon, R. M. (1986). Folk psychology as simulation. Mind Lang. 1, 158-171.

Griffiths, P., and Scarantino, A. (2009). "Emotions in the wild: the situated perspective on emotion," in The Cambridge Handbook of Situated Cognition, eds P. Robbins 
and M. Aydede (Cambridge, MA: Cambridge University Press), 437-453.

Grossman, J. B., Klin, A., Carter, A. S., and Volkmar, F. R. (2000). Verbal bias in recognition of facial emotions in children with Asperger syndrome. J. Child Psychol. Psychiatry 41, 369-379.

Gump, B. B., and Kulik, J. A. (1997). Stress, affiliation, and emotional contagion. J. Pers. Soc. Psychol. 72, 305-319.

Hatfield, E., Cacioppo, J. T., and Rapson, R. L. (1994). Emotional Contagion. Cambridge, MA: Cambridge University Press.

Havas, D. A., Glenberg, A. M., Gutowski, K. A., Lucarelli, M. J., and Davidson, R. J. (2010). Cosmetic use of botulinum toxin-a affects processing of emotional language. Psychol. Sci. 21, 895-900.

Hayes, D. P., and Cobb, C. (1982). "Cycles of spontaneous conversation and long-term isolation," in Interaction Rythms: Periodicity in Communicative Behavior, ed $\mathrm{M}$. Davis (New York, NY: Human Sciences), 319-339.

Hemmesch, A. R., Tickle-Degnen, L., and Zebrowitz, L. A. (2009). The influence of facial masking and sex on older adults' impressions of individuals with Parkinson's disease. Psychol. Aging 24, 542.

Hermelin, B., and O'Connor, N. (1985). "Logico-affective states and nonverbal language" in Communication Problems in Autism, eds E. Schopler and G. Mesibov (New York, NY: Plenum Press), 283-310.

Herschbach, M. (2011). Mirroring versus simulation: on the representational function of simulation. Synthese.

Hess, U. (1998). "Mimicry: fact and fiction," in Proceedings of the Xth Conference of the International Society for Research on Emotion (Wurzburg, Germany)

Hess, U., Kappas, A., McHugo, G. J., Lanzetta, J. T., and Kleck, R. E. (1992). The facilitative effect of facial expression on the selfgeneration of emotion. Int. J. Psychophysiol. 12, 251-265.

Hess, U., and Bourgeois, P. (2010). "You smile-I smile: emotion expression in social interaction. Biol. Psychol. 84, 514-520.

Hobson, R. P., Chidambi, G., Lee, A., and Meyer, J. (2006). Foundations for self-awareness: an exploration through autism. Monogr. Soc. Res. Child Dev. 71

Hove, M. J., and Risen, J. L. (2009). It's all in the timing: interpersonal synchrony increases affiliation. Soc. Cogn. 27, 949-960.

Hutto, D. D. (2004). The limits of spectatorial folk psychology. Mind Lang. 19, 548-573.

Iacoboni, M., Koski, L. M., Brass, M., Bekkering, H., Woods, R. P., Dubeau, M-C., Mazziotta, J. C., and Rizzolatti, G. (2001). Reafferent copies of imitated actions in the right superior temporal cortex. Proc. Natl. Acad. Sci. U.S.A. 98, 13995-13999.

Izard, C. E. (1971). The Face of Emotion. New York, NY: Appleton-CenturyCrofts.

Izard, C. E. (1974). Emotions, Human. Encyclopedia Britannica, 248-256.

de Jaegher, H. (2009). Social understanding through direct perception? Yes, by interacting. Conscious. Cogn $18,535-542$.

de Jaegher, H., and Di Paolo, E. (2007). Participatory sense-making. Phenomenol. Cogn. Sci. 6, 485-507.

de Jaegher, H., Di Paolo, E., and Gallagher, S. (2010). Can social interaction constitute social cognition? Trends Cogn. Sci. 14, 441-447.

de Jaegher, H., and Froese, T. (2009). On the role of social interaction in individual agency. Adapt. Behav. 17, 444-460.

Johnson, M. H., Suzanne, D., Hadyn, E., and John, M. (1991). "Newborns" preferential tracking of face-like stimuli and its subsequent decline. Cognition 40, 1-19.

Jones, S. S. (2009). The development of imitation in infancy. Philos. Tran. R. Soc. B Biol. Sci. 364, 2325-2335.

Jones, S. S., Collins, K., and Hong, H. W. (1991). An audience effect on smile production in 10-month-old infants. Psychol. Sci. 2, 45-49.

Kanwisher, N., Josh, M., and Chun, M. M. (1997). The fusiform face area: a module in human extrastriate cortex specialized for face perception. J. Neurosci. 17, 4302-4311.

Keillor, J. M., Barrett, A. M., Crucian, G. P., Kortenkamp, S., and Heilman, K. M. (2002). Emotional experience and perception in the absence of facial feedback. J. Int. Neuropsychol. Soc. 8, 130-135.

Klin, A., Jones, W., Schultz, R., Volkmar, F., and Cohen, D. (2002). Visual fixation patterns during viewing of naturalistic social situations as predictors of social competence in individuals with autism. Arch. Gen. Psychiatry 59, 809-816.

Knoblich, G., and Sebanz, N. (2008). Evolving intentions for social interaction: from entrainment to joint action. Philos. Trans. R. Soc. Lond. B Biol. Sci. 363, 2021-2031.

Kraut, R. E., and Johnston, R. E. (1979). Social and emotional messages of smiling: an ethological approach. $J$. Pers. Soc. Psychol. 37, 1539-1553.

Krueger, J. (2011). Extended cognition and the space of social interaction. Conscious. Cogn. 20, 643-657.

Krueger, J. (forthcoming). "Emotions and other minds," in Interiority/Exteriority: Rethinking Emotion, eds R. Campe, and J. Weber (New York, NY: Walter de Gruyter).

Laird, J. D. (2007). Feelings: The Perception of Self. Oxford: Oxford University Press.

Lakin, J., and Chartrand, T. (2003) Using nonconscious behavioral mimicry to create affiliation and rapport. Psychol. Sci. 14, 334-339.

Lang, P. J., Greenwald, M. K., Bradley, M. M., and Hamm, A. O. (1993). Looking at pictures: affective, facial, visceral, and behavioral reactions. Psychophysiology 30 261-273.

Lanzetta, J. T., and Englis, B. G. (1989). Expectations of cooperation and competition and their effects on observers' vicarious emotional responses. J. Pers. Soc. Psychol. 56 543.

Lawrence, A. D., Calder, A. J., McGowan, S. W., and Grasby, P. M. (2002). Selective disruption of the recognition of facial expressions of anger. Neuroreport 13, 881.

LeDoux, J. E. (1996). The Emotional Brain. New York, NY: Simon and Shuster.

Lehnhardt, F. G., Gawronski, A. Volpert, K., Schilbach, L., Tepest, R., Huff, W., and Vogeley, K. (2011). Autismus-Spektrum-Stärungen im Erwachsenenalter: klinische und neuropsychologische Befunde spätdiagnostizierter Asperger-Syndrome. Fortschr. Neurologis. Psychiatr. $79,1-8$.

Leslie, K. R., Johnson-Frey, S. H., and Grafton, S. T. (2004). Functional imaging of face and hand imitation: towards a motor theory of empathy. Neuroimage 21, 601-607.

Levinas, E., (1969). Totality and Infinity: An Essay on Exteriority. Trans. Alphonso Lingis. Pittsburgh: Duquesne University Press.

Lipps, T. (1907). Das Wissen von fremden Ichen. Psychol. Untersuchungen 1, 694-722.

Lundqvist, L-O., and Dimberg, U. (1995). Facial expressions are contagious. J. Psychophysiol. 9, 203-211.

Lyons, K. D., Tickle-Degnen, L., Henry, A., and Cohn, E. (2004).
Impressions of personality in Parkinson's disease: can rehabilitation practitioners see beyond the symptoms? Rehabil. Psychol. 49, 328.

Marsh, K. L., Johnston, L., Richardson, M. J., and Schmidt, R. C. (2009). Toward a radically embodied, embedded social psychology. Eur. J. Soc. Psychol. 39, 1217-1225.

Matsumoto, D., and Willingham, B. (2009). Spontaneous facial expressions of emotion of congenitally and noncongenitally blind individuals. J. Pers. Soc. Psychol. 96, 1.

Matsumoto, D., and Ekman, P. (2006). Multi-Ethnic Facial Expression Set. Unpublished images.

McHugo, G. J., Lanzetta, J. T., and Bush, L. K. (1991). The effect of attitudes on emotional reactions to expressive displays of political leaders. J. Nonverbal Behav. 15, 19-41.

Mehrabian, A. (1971). Silent Messages. Belmont, CA: Wadsworth.

Meltzoff, A., and Moore, K. (1977). Imitation of facial and manual gestures by human neonates. Science 198, 75-78.

Meltzoff, A. N., and Moore, M. K. (1989). Imitation in newborn infants: exploring the range of gestures imitated and the underlying mechanisms. Dev. Psychol. 25, 954-962.

Meltzoff, A., and Moore, K. (1997). Explaining facial imitation: a theoretical model. Early Dev. Parent. 6, 179-192.

Meyerson, M. D. (2001). Resiliency and success in adults with Moebius syndrome. Cleft Palate-Craniofac. J. 38, 231-235.

Michael, J. (2011). Interaction and mindreading. Rev. Philos. Psychol. 2, 559-578.

Mondloch, C. J., Lewis, T. L., Robert Budreau, D., Maurer, D., Dannemiller, J. L., Stephens, B. R., and Kleiner-Gathercoal, K. A. (1999). Face perception during early infancy. Psychol. Sci. 10, 419-422.

Müller, B., Kühn, S., van Baaren, R., Dotsch, R., Brass, M., and Dijksterhuis, A. (2011). Perspective taking eliminates differences in corepresentation of out-group members' actions. Exp. Brain Res. 211, 423-428.

Murray, L., and Trevarthen, C. (1985). "Emotional regulation of interactions between two month-olds and their mothers," in Social Perception in Infants, ed. T. M. Field and N. Fox (Norwood, NJ: Ablex).

Nelson, C. A. (2001). The development and neural bases of face recognition. Infant Child Dev. 10, 3-18. 
Neville, H. J., and Bavelier, D. (2000). "Specificity and plasticity in neurocognitive development in humans," in The New Cognitive Neurosciences, ed. M. Gazzaniga, 2nd Edn. (Cambridge, MA: MIT Press), 83-98.

Niedenthal, P. M. (2007). Embodying emotion. Science 316, 1002-1005.

Niedenthal, P. M., Brauer, M., Halberstadt, J. B., and InnesKer, A. H. (2001). When did her smile drop? Facial mimicry and the influences of emotional state on the detection of change in emotional expression. Cogn. Emot. 15, 853-864.

Niedenthal, P. M., Lawrence, W., Barsalou, P. W., Silvia, K.-G., and Francois, R. (2005). Embodiment in attitudes, social perception, and emotion. Pers. Soc. Psychol. Rev. 9, 184-211.

Öhman, A. (2002). "Automaticity and the amygdala: nonconscious responses to emotional faces." Curr. Dir. Psychol. Sci. 11, 62-66.

Osterling, J., Dawson, G., and Munson, J. (2002). Early recognition of 1-year-old infants with autism spectrum disorder versus mental retardation. Dev. Psychopathol. 14, 239-251.

Oullier, O., De Guzman, G. C., Jantzen, K. J., Lagarde, J., and Kelso, J. A. S. (2008). Social coordination dynamics: measuring human bonding. Soc. Neurosci. 3, 178-192.

Overgaard, S., and Michael, J. (Under review). "The interactive turn: a critique”.

Perner, J. (1991). Understanding the Representational Mind. Cambridge, MA: MIT Press.

Premack, D., and Woodruff, G. (1978). "Does the chimpanzee have a theory of mind?" Behav. Brain Sci. 1, 515-526.

Ratcliffe, M. (2007). Rethinking Commonsense Psychology: A Critique of Folk Psychology, Theory of Mind, and Simulation. New York, NY: Palgrave Macmillan.

Reissland, N., Francis, B., Mason, J., and Lincoln, K. (2011). "Do facial expressions develop before birth?" PLoS One 6:e24081. doi: 10.1371/journal.pone.0024081

Richardson, M. J., Marsh, K. L., Isenhower, R. W., Goodman, J. R., and Schmidt, R. C. (2007). Rocking together: dynamics of intentional and unintentional interpersonal coordination. Hum. Mov. Sci. 26, 867-891.

Rumsey, N., Clarke, A., White, P., Wyn-Williams, M., and Garlick, W. (2004). Altered body image: appearance-related concerns of people with visible disfigurement. $J$. Adv. Nurs. 48, 443-453.

Sacks, O. (1995). An Anthropologist on Mars. New York, NY: Alfred A. Knopf.

Scheflen, A. (1964). The significance of posture in communication systems. Psychiatry 27, 316-331.

Scheler, M. (1954). The Nature of Sympathy. Trans. Peter Heath. London: Routledge and Kegan Paul. Schmidt, R. C., and Richardson, M. J. (2008). "Dynamics of interpersonal coordination," in Coordination: Neural, Behavioral and Social Dynamics, eds A. Fuchs and V. K. Jirsa (Berlin: Springer-Verlag), 281-308.

Senju, A., Johnson, M. H., and Csibra, G. (2006). The development and neural basis of referential gaze perception. Soc. Neurosci. 1, 220-234.

Slater, A., and Quinn, P. C. (2001). Face recognition in the newborn infant. Infant Child Dev. 10, 21-24.

Smart, J. (2008). Disability, Society, and the Individual. Austin, TX: Pro-Ed.

Smith, A. (1759). The Theory of Moral Sentiments. New York, NY: Augustus M. Kelley.

Soussignan, R. (2002). "Duchenne smile, emotional experience, and autonomic reactivity: a test of the facial feedback hypothesis." Emotion $2,52-74$.

Spiridon, M., and Kanwisher, N. (2002). How distributed is visual category information in human occipito-temporal cortex? An fMRI study. Neuron 35, 1157-1165.

Spivey, M. (2007). The Continuity of Mind. Oxford: Oxford University Press.

Stel, M., van Dijk, E., and Olivier, E. (2009). "You want to know the truth? Then don't mimic!" Psychol. Sci. 20, 693-699.

Stern, D. (2002/1977). The First Relationship: Infant and Mother. London: Harvard University Press.

Stern, D. (1985/1998). The Interpersonal World of the Infant: A View from Psychoanalysis and Developmental Psychology. New York, NY: Basic Books.

Sutton, J., Christensen, W., and Geeves, A. (2011). Applying intelligence to the reflexes: embodied skills and habits between dreyfus and descartes. J. Br. Soc. Phenomenol. 42 , 78-101.

Thompson, E. (2007). Mind in Life: Biology, Phenomenology, and the Sciences of Mind. Cambridge, MA: Harvard University Press.

Tickle-Degnen, L., and Lyons, K. D. (2004). Practitioners' impressions of patients with Parkinson's disease: the social ecology of the expressive mask. Soc. Sci. Med. 58, 603-614.

Timmermans, B., Barisic, I., Vogeley, K., and Schilbach, L. (in press). Can you feel me? A different sensitivity to interaction dynamics in highfunctioning autism.

Trevarthen, C. (1979). "Communication and cooperation in early infancy: a description of primary intersubjectivity," in Before Speech, ed M. Bullowa (Cambridge: Cambridge University Press), 321-347.

Tronick, E., Als, H., Adamson, L., Wise, S., and Brazelton, T. B. (1978). The infant's response to entrapment between contradictory messages in face-to-face interaction. J. Am. Acad. Child Psychiatry 17, $1-13$.

van Ulzen, N. R., Claudine, J. C. Lamoth, A. D., Gun, R. S., and Peter, J. B. (2008). Characteristics of instructed and uninstructed interpersonal coordination while walking side-by-side. Neurosci. Lett. 432, 88-93.

Valdesolo, P., Ouyang, J., and DeSteno, D. (2010). The rhythm of joint action: synchrony promotes cooperative ability. J. Exp. Soc. Psychol. 46, 693-695.

van Swearingen, J. M., Cohn, J. F., and Bajaj-Luthra, A. (1999). Specific impairment of smiling increases the severity of depressive symptoms in patients with facial neuromuscular disorders. Aesthetic Plast. Surg. 23, 416-423.

van Swearingen, J. M., Cohn, J. F., Turnbull, J., Mrzai, T., and Johnson, P. (1998). Psychological distress: linking impairment with disability in facial neuromotor disorders. Otolaryngol. Head Neck Surg. 118, 790-796.

Walton, G. E., Bower, N. J. A., and Bower, T. G. R. (1992). Recognition of familiar faces by newborns. Infant Behav. Dev. 15, 265-269.
Weeks, S. J., and Hobson, R. P. (1992). The salience of facial expression for autistic children. J. Child Psychol. Psychiatry Allied Discip. 28, 137-151.

Weiss, T., Wolfgang, H. R., Miltner, R. H., Reinhard, F., Ingo, S., and Edward, T. (2000). Rapid functional plasticity of the somatosensory cortex after finger amputation. Exp. Brain Res. 134, 199-203.

Williams, D., and Happé, F. (2010). Representing intentions in self and other: studies of autism and typical development. Dev. Sci. 13, 307-319.

Wiltermuth, S. S., and Heath, C. (2009). Synchrony and cooperation. Psychol. Sci. 20, 1-5.

Winfree, A. T. (2001). The Geometry of Biological Time, 2nd Edn. New York, NY: Springer-Verlag.

Wright, B., Clarke, N., Jordan, J. Young, A. W. Clarke, P., Miles, J., Nation, K., Clarke, L., and Williams, C. (2008). Emotion recognition in faces and the use of visual context in young people with high-functioning autism spectrum disorders. Autism $12,607-626$.

Zahavi, D., and Parnas, J. (2003). Conceptual problems in infantile autism research: why cognitive science needs phenomenology. J. Conscious. Stud. 10, 53-71.

Zivotofsky, A. Z., and Hausdorff, J. M. (2007). J. Neuroeng. Rehabil. 4, 28.

Conflict of Interest Statement: The authors declare that the research was conducted in the absence of any commercial or financial relationships that could be construed as a potential conflict of interest.

Received: 22 December 2011; paper pending published: 20 February 2012; accepted: 22 March 2012; published online: 11 April 2012.

Citation: Krueger J and Michael J (2012) Gestural coupling and social cognition: Möbius Syndrome as a case study. Front. Hum. Neurosci. 6:81. doi: 10.3389/ fnhum.2012.00081

Copyright (c) 2012 Krueger and Michael. This is an open-access article distributed under the terms of the Creative Commons Attribution Non Commercial License, which permits non-commercial use, distribution, and reproduction in other forums, provided the original authors and source are credited. 